\title{
Between guilt and obligation: debating the responsibility for climate change and climate politics in the media
}

Post, Senja ; Kleinen-von Königslöw, Katharina ; Schäfer, Mike S

\begin{abstract}
The "common but differentiated responsibility" of developed and developing countries to mitigate climate change is a core principle of international climate politics-but there is disagreement about what this "differentiated responsibility" amounts to. We investigate how newspapers in developed countries (Australia, Germany, United States) and emerging economies (Brazil, India) covered this debate during the UN climate summits in 2004, 2009, and 2014. Newspapers in both types of countries attributed more responsibility to developed than to developing countries. In line with social identity theory, however, media in developed countries attributed less causal responsibility (blame) to other developed countries than media in emerging economies. The latter countries' media, in turn, attributed less responsibility to other developing countries than media in developed countries. At the same time, in line with the "differentiated responsibility", media in developed countries attributed more responsibility to their own countries than media in emerging economies.
\end{abstract}

DOI: https://doi.org/10.1080/17524032.2018.1446037

Posted at the Zurich Open Repository and Archive, University of Zurich

ZORA URL: https://doi.org/10.5167/uzh-159682

Journal Article

Accepted Version

Originally published at:

Post, Senja; Kleinen-von Königslöw, Katharina; Schäfer, Mike S (2018). Between guilt and obligation: debating the responsibility for climate change and climate politics in the media. Environmental Communication:1-17.

DOI: https://doi.org/10.1080/17524032.2018.1446037 


\title{
Between Guilt and Obligation:
}

\section{Debating the Responsibility for Climate Change and Climate Politics in the Media}

\begin{abstract}
The "common but differentiated responsibility" of developed and developing countries to mitigate climate change is a core principle of international climate politics - but there is disagreement about what this "differentiated responsibility" amounts to. We investigate how newspapers in developed countries (Australia, Germany, USA) and emerging economies (Brazil, India) covered this debate during the UN climate summits in 2004, 2009 and 2014. Newspapers in both types of countries attributed more responsibility to developed than to developing countries. In line with social identity theory, however, media in developed countries attributed less causal responsibility (blame) to other developed countries than media in emerging economies. The latter countries' media, in turn, attributed less responsibility to other developing countries than media in developed countries. At the same time, in line with the "differentiated responsibility", media in developed countries attributed more responsibility to their own countries than did media in emerging economies.
\end{abstract}

Keywords: Attribution of Responsibility, Climate change communication, Climate politics, Quantitative content Analysis, Internationally comparative, Social Identity Theory 


\section{Between Guilt and Obligation:}

\section{Debating the Responsibility for Climate Change and Climate Politics in the Media}

In the mid-2000s, the international community entered a new period of controversial negotiations of global climate change policies. Acknowledging the responsibility for climate change of industrialized countries, the international community had exempted developing countries from obligations to cap greenhouse gas emissions under the Kyoto Protocol, which had been ratified in 1997 and became effective in early 2005 (for an overview see Gupta, 2010). In the international negotiations of a deal that followed the enactment of the Kyoto Protocol, the roles of formerly developing and newly emerging economies such as Brazil, China, India, and South Africa became strongly contested due to their rapid economic growth and corresponding rise in greenhouse gas emissions (Hallding, Jürisoo, Carson \& Atteridge, 2013). Thus, between 2004 and 2015, while the international community was negotiating an agreement supplanting the Kyoto Protocol, the international debate was marked by a debate about how the traditional industrialized countries and former developing, newly emerging economies should equitably share the burden of climate change mitigation (Genovese, 2014; Brunée \& Streck, 2013; Friman \& Hjerpe. 2015; Schmidt \& Schäfer, 2015).

In international negotiations, policymakers have to be responsive to the national publics they represent. For this reason, it can be assumed that the success of international negotiations partly depends on the degree to which national media debates articulate converging views of international negotiations - e.g., of the problems at stake, countries' obligations and responsibilities, their goals and national interests, and so on. As most people lack direct experience with international negotiations, they rely heavily on news coverage, which is mainly organized in national media systems (Hallin \& Mancini, 2004); thus, national news likely influences how citizens perceive international negotiations and how legitimate they consider national as well as foreign demands and arguments (Michaelowa \& Michaelowa, 2012; Kleinen-von Königslöw, Post \& Schäfer, 2017). National news coverage 
thus likely serves as a point of reference for national policymakers. It therefore seems crucial to analyze national news coverage of international negotiations.

Some researchers have applied social identity theory (Tajfel \& Turner, 1986) to explain differences across national media debates (Jones \& Sheets, 2009; Müller, 2013, 2016; Olausson, 2010; Rivenburgh, 2000). They propose that in covering national or foreign issues, journalists engage in national identity building by distinguishing their respective countries from foreign countries, and by presenting their own in more favorable ways. While these studies suggest that the application of social identity theory is a fruitful approach to explaining similarities and differences across national media debates, it has never been applied to the context of international negotiations. This is surprising because social identity theory offers powerful explanations of diverging views in intergroup conflicts (Esses, Jackson, \& Bennett-AbuAyyash, 2011). In the present study, we apply social identity theory as a framework to investigate differences in news coverage of countries' responsibilities related to climate change and climate change politics between traditional developed countries (for the sake of simplicity, henceforth called "developed countries") and former developing countries that have newly emerging economies (henceforth called "emerging economies"). The context of our study is the national media coverage of the climate conferences (COPs) in Buenos Aires (2004), Copenhagen (2009), and Lima (2014) as disseminated in three developed countries (Australia, Germany, the United States) and two emerging economies (Brazil, India).

\section{Responsibility for climate change as a conflict issue in international negotiations}

In the early 1990s, the United Nations Framework Convention on Climate Change (UNFCCC) was established to set the rules for international climate change negotiations. It includes annual meetings (Conferences of the Parties, COPs) where the member states discuss climate change policies with the goal of creating legally binding obligations to reduce 
greenhouse gas emissions. These negotiations first led to the Kyoto Protocol, which set legally binding emission reduction targets for the signatory states, and later to the Paris Agreement, with 195 states committing limiting the rise of the global average temperature to 1.5 degrees Celsius.

From the start, the UNFCCC distinguished between rich and poor countries, stating that because "the largest share of historical and current global emissions of greenhouse gases has originated in developed countries," there exist "common but differentiated responsibilities" (UN, 1992) to engage in mitigation efforts (cf. Brunée \& Streck, 2013; Friman \& Hjerpe, 2015). Accordingly, under the Kyoto Protocol, the developed countries plus the then economies in transition, such as the former Soviet states, were obliged to reduce their greenhouse gas emissions. They were listed in Annex I of the Convention and in Annex B of the Kyoto Protocol. By contrast, the developing countries were exempt from any such obligations. They were listed neither in Annex I of the Convention nor in the Annex B of the Kyoto Protocol.

In the years following the Kyoto Protocol, the distinction between Annex I and nonAnnex I countries came to be contested as the former developing countries with newly emerging economies, such as Brazil, China, India and South Africa, were increasingly expected to limit their greenhouse gas emissions (cf. Broadbent et al., 2016; Johannessen, 2015). While acceptance of the developed countries' "historic responsibility" to adopt mitigation policies grew in the international community (cf. Friman \& Hjerpe, 2015, p. 305), there have been controversial debates as to what this historical responsibility amounts to and to what degree former developing countries should join these efforts (e.g., Billett, 2010; Johannessen, 2015). Surveys of delegates at two COPs (2011 in Durban and 2012 in Doha) show that a majority of them, particularly those from developing countries, tend to embrace a “proportional” view of the developed countries' historic responsibility postulating that countries' mitigation burdens should be proportional to their historical contributions to 
climate change either since pre-industrial times or since 1990, when emissions of greenhouse gases were officially acknowledged as a major driver of anthropogenic climate change by the international community. By contrast, in line with the difficulties of quantifying equitable contributions to climate change mitigation (cf. Füssel, 2010; Huggel, Wallimann-Helmer, Stone \& Cramer, 2016), some delegates, particularly from developed countries, prefer a "conceptual view" of the developed countries' historical responsibility, arguing "that developed countries have a moral responsibility to lead in combating climate change (...) but not necessarily in proportion to their contributions" (Friman \& Hjerpe, 2015, p. 306). Thus, although international consensus concerning countries' differing obligations to mitigate climate change has been reached, debate persists concerning how these differences should be translated into specific obligations (Bernauer, 2013). This raises the question as to how the conflict about responsibilities for climate change and climate change mitigation has been presented in national media debates (Billett, 2010; Schmidt \& Schäfer, 2015).

\section{Social identity theory as an explanation of differing national media debates}

Some researchers have applied social identity theory as a framework to explain differences across national media debates (Jones \& Sheet, 2009; Müller, 2013, 2016; Olausson, 2010; Rivenburgh, 2000). A social psychological theory, it predicts that individuals derive parts of their identities from their belonging to different social groups (Tajfel \& Turner, 1986) and maintain their self-esteem by distinguishing their own groups (in-groups) from other groups (out-groups). In doing so, they often use self-serving tactics, e.g., favorable evaluations of their in-groups or derogative evaluations of their out-groups (e.g., Leyens \& Demoulin, 2011). In-group-favoring and out-group-derogating judgments can be understood to function as in-group protection against out-group threats in conflicts (Fiske \& Russell, 2011). Authors have argued that social identity theory can be applied to explain differences across national media debates for two reasons. First, when journalists deal with international 
affairs, their own cultural and national identities become salient and find expression in their news judgments (Jones \& Sheets, 2009; Müller, 2016; Rivenburgh, 2000). Second, journalists anticipate the needs of their audience and are sensitive to its "cultural and national identity concerns in deciding how to report the news" (Jones \& Sheets, 2009, p. 279; see also Müller, 2013; Rivenburgh, 2000). As a result, one might expect patterns of national news coverage that favor countries' in-groups and derogate countries' out-groups.

Studies have confirmed such patterns. For example, in a comparative analysis of German and U.S. news coverage of national elections in both countries, both the German and the U.S. media portrayed their respective national electorates as less susceptible to media influences than the foreign electorate- suggesting the domestic electorate was more resistant to negative media effects than the foreign electorate (Müller, 2013). Jones \& Sheefer (2009) analyzed newspaper coverage of the Abu Ghraib prison scandal in seven countries, showing that the U.S. newspapers made judgments that protected national self-esteem-e.g., by avoiding the word "torture". While the U.S. media used the word in only 19 percent of the news sources analyzed - instead preferring words like "misconduct" - foreign newspapers used it in 66 percent of their news articles. In his classic study on news framing, Entman (1993) found a similar in-group-protecting pattern in news coverage of the downings of an Iranian plane by a U.S. Navy ship and of a Korean jet by a Soviet fighter plane. While U.S. news magazines described the downing of the Iranian plane by the U.S. Navy as a technical problem, they portrayed the downing of the Korean jet by the Soviet military as an intentional and morally outrageous action.

Studies further showed that countries' in-groups and out-groups in the news need not be limited to national borders but can be extended to groups of countries - e.g., culturally close versus distant ones. For example, reporting on Abu Ghraib, media in non-anglophone countries used the term "torture" twice as often ( 82 percent) as media in anglophone countries (Jones \& Sheefer, 2009). Similarly, reporting on citizens' susceptibility to media effects, 
national media portrayed citizens in neighboring states (e.g. the French electorate in German news media or the Canadian electorate in U.S. news media) as less susceptible than citizens in distant states (e.g. the U.S. electorate in German news media or the German electorate in U.S. news media; Müller, 2013).

To the best of our knowledge, social identity theory has never been applied to explain national news coverage of international negotiations. This is surprising because conflicts or competition between groups is considered conducive to in-group / out-group biases (Esses et al., 2011). Based on this, it is plausible to assume that in the international conflict about countries' responsibilities for climate change and climate change politics, in-group / outgroup processes will find expression in national news coverage.

\section{Attributions of responsibility in transnational media debates about climate politics}

Attributions of responsibility can be used in ways that favor or protect in-groups and derogate out-groups. To assess such attributions, researchers have distinguished between causal and treatment responsibility. Causal responsibility "focuses on the origins of an issue, while treatment responsibility focuses on the alleviation of the issue" (Iyengar 1989, p. 878; see also Gerhards, Offerhaus, \& Roose, 2009). Though most researchers looking at attributions of (mainly causal) responsibility in media debates did not explicitly refer to social identity theory, they did show patterns of in-group favoritism and / or out-group derogation. Gerhards et al. (2009) looked at attributions of responsibility in British and German news coverage of the European Union and found that members of the respective national governments largely blamed the EU for failures while praising themselves for successes. In contrast, EU officials largely blamed the national governments for failures while praising the EU for successes. Other researchers explicitly focused on the media's roles in presenting actors' attributions of responsibility. Studies showed that national media accounts of international events do not only diverge due to journalists' explicit evaluations or judgments, 
but also due to their different weightings of facts or sources (Kepplinger \& Lemke, 2015). In line with this reasoning, Rivenburgh (2000) found that national newspapers in Argentina, Denmark and the U.S. reported with an in-group favoring tendency by playing up events in the news in which national citizens involved were successful (e.g., sports events).

As was mentioned, in the period from the enactment of the Kyoto Protocol to the postCopenhagen negotiations, the emerging economies were increasingly expected to participate in mitigation efforts (cf. Broadbent et al., 2016; Johannessen, 2015). As a result, the media in these countries paid more attention to global climate politics and to the expectations from developed countries - thereby creating impressions of an out-group threat (Billett, 2010; Broadbent et al., 2016). At the same time, the Indian media-and possibly the media in other emerging economies as well—provided a strong in-group orientation by articulating an attitude that was "empathetic towards the situation in other emerging and developing economies" and that "framed these countries as being in a similar position to India on climate change" (Billett, 2010, p. 12). One can thus assume that in the international conflict about climate politics between the enactment of the Kyoto Protocol and the Paris Agreement, the developed countries and emerging economies formed two conflicting groups (Hallding et al., 2013) and that the domestic media in both groups of countries presented the debate in ways that favored or protected their in-groups.

Though research on this question is scarce, some studies have hinted at such patterns. In general, there is more evidence of in-group-favoring attributions of responsibility in the news media in emerging economies than in developed countries. For example, in the period from 2002 to 2007, Indian newspapers largely blamed developed countries for causing climate change and expected them to solve it (Billett, 2010). This perspective was also typical of other developing countries or countries with newly emerging economies, such as Brazil, China, and Mexico, in the years preceding the COP 15 in Copenhagen (Broadbent et al., 2016). This view also existed in Chinese TV news during the negotiations in Copenhagen, 
when journalists largely claimed that the developed countries were in charge of solving the climate problem and shifted the blame for causing climate change away from China to other countries (Liang et al., 2014).

Media coverage in developed countries, by contrast, largely relieved developing countries of the burden of climate change mitigation. For example, between 2004 and 2005, Swedish newspaper coverage largely put the task of reducing greenhouse gas emissions in the hands of developed countries (Olausson, 2009). This is in line with Canadian and U.S. TV news coverage of the climate summit in Copenhagen, which predominantly presented their own countries or other developed countries as responsible for climate change mitigation (Laing et al., 2009). While such attributions are largely in line with the principle of "common but differentiated responsibilities," there are also hints at in-group-protecting attributions. In news coverage of the COPs in 2011, 2012, and 2013, the largest share of news reports in German opinion-leading media held both the developed and developing countries responsible for climate change mitigation (Haßler, 2016).

In sum, research suggests that news coverage both in developed countries and emerging economies has been largely in line with the principle of "a common but differentiated responsibility" for climate change. Other studies suggest that in-group-favoring attributions of responsibility might have played a role in the national news of both groups of countries as well (e.g., Billett, 2010; Broadbent et al., 2016; Haßler, 2016; Liang et al., 2014). Yet existing research is too diverse and fragmented in terms of the countries, media and time periods analyzed to illuminate to what degree in-group favoring patterns were present in the national news coverage in developed countries and emerging economies.

What is more, based on existing research we cannot tell whether attributions of responsibility shifted over time. Social identity theory holds that in-group / out-group perceptions can be reduced when group constellations change, e.g. because the members of conflicting groups start to identify with superordinate groups (Gaertner, Dovidio \& Houlette, 
2010). An example of this was found in Swedish news coverage of the international climate change negotiations. In addition to the Swedish national identity the news media largely stressed a common European identity and thereby implied broad similarities between the European countries' stances on climate change politics (Olausson, 2010). Some authors have argued that because climate change cannot be solved on a national level, international climate change politics might give rise to a global public sphere (u.a. Beck, 2007, 34; Eide \& Kunelius, 2010). If this holds true, then any in-group / out-group distinctions in national news reports on climate change can be expected to have lessened over time.

\section{Research Assumptions}

Against the backdrop of the historical development of the climate change negotiations and based on the research cited, we assume that the media in developed countries and emerging economies have followed the premise of "common but differentiated responsibilities" while nevertheless using attributions of responsibility in ways that favor or protect their nations or their respective in-groups. We pose four hypotheses.

Because of the consensus on the traditional developed countries" "historic responsibility" for climate change, i.e., their responsibility for having caused climate change and their consequent duty to mitigate climate change, we assume that:

H1: Media in traditional developed countries attributed responsibility to their own countries more often than did media in countries with emerging economies.

As mentioned, after the Kyoto Protocol, a conflict emerged between developed countries and emerging economies over each group of countries' responsibilities for climate change. Based on the theoretical considerations and empirical findings related to in-group favoritism in transnational media debates, we assume that the national media of the developed countries and emerging economies attributed responsibility to their in-group less often than the media of their out-group, that is: 
H 2a: Media in developed countries attributed responsibility to other developed countries less often and to developing countries more often than media in countries with emerging economies. Conversely,

$\mathrm{H} 2 \mathrm{~b}$ : media in countries with emerging economies attributed responsibility to developed countries more often and to developing countries or emerging economies less often than did media in developed countries.

Because of the developed countries' widely acknowledged "historic responsibility for climate change" we further expect that in-group favoritism in the media of developed countries finds its limit within the principle of a "common but differentiated responsibility" of developed and developing countries, that is:

H3a: Media in developed countries attributed responsibility to their in-group (their own and other developed countries) more often than to their out-group (developing countries and countries with emerging economies), while

H3b: media in emerging economies attributed responsibility to their out-group (developed countries) more often than to their in-group (their own and other developing countries or emerging economies).

As mentioned above, some authors expect that climate politics will give rise to a global public sphere, resulting in a shared view on the problem. This suggests that the conflict between developed countries and countries with emerging economies might weaken and that climate change might increasingly be regarded as a common responsibility. We therefore test whether

H4: Media in developed countries and in emerging economies attributed responsibility increasingly equally to their respective in- and out-groups. 


\section{Method}

\section{Media sample and time frame}

This study is based on a quantitative content analysis of news coverage of the COPs in 2004 (Buenos Aires), 2009 (Copenhagen), and 2014 (Lima) in opinion-leading national newspapers in three traditional developed and two former developing countries. We focused on news coverage of the COPs, as they represent core events for international climate politics (Gupta 2010) and are intensively covered in the media (Schmidt et al., 2013; Schäfer et al., 2014). Among traditional developed countries, we chose Australia, Germany, and the United States of America. Among former developing countries with newly emerging economies, we chose Brazil and India, which had been exempt from obligations to limit greenhouse gas emissions under the Kyoto regime.

For each country, we analyzed one liberal-leaning and one conservative-leaning newspaper (see below). We obtained the relevant articles from the LexisNexis and Factiva databases. ${ }^{1}$ We sought to identify all the newspaper articles on climate change politics that were published from one week before until one week after each COP. ${ }^{2}$ As a first step, we drew all the newspaper articles from LexisNexis and Factiva that contained the terms climate, climate change, or global warming. In a second step, for the sake of compatibility, we deleted all news articles that originated from news agencies because newspapers have very different policies of submitting agency-based articles to the LexisNexis and Factiva databases (Snider \& Janda 1998). Thus, our data is based on newspaper articles authored by the newspapers' own staff. In the third step, we developed a complex search string in English, German, and Portuguese based on which we could differentiate articles on climate change politics from articles on other subjects (e.g., pure climate science). To evaluate our search string, we compared our search results with a manual classification of about 100 articles and calculated accuracy (the share of articles that were classified correctly as relevant or irrelevant by the search filter), precision (the degree to which articles that were identified as relevant for 
climate politics were correctly identified), recall (the ratio of articles coded as relevant to all relevant articles in the sample), and F-values (the harmonic mean of precision and recall (Scharkow, 2012)). For all measures, we obtained values well above 0.85 for all languages, which indicates that our search strings were reliable.

We identified 316 articles in The Australian and 228 in The Sydney Morning Herald, 169 in the O Estado do São Paulo and 167 in the Folha de São Paulo, 257 in the Frankfurter Allgemeine Zeitung and 316 in the Süddeutsche Zeitung, 137 in The Hindu and 127 in The Times of India, 113 in The New York Times, and 108 in The Washington Post. For our manual content analysis, we drew samples of 20 articles per newspaper and year. In some years, some newspapers published fewer than 20 articles. In this case, we analyzed all articles.

\section{Coding procedure}

Our analysis is based on attributions of blame for and obligation to contribute to solving the problem of climate change. Following Gerhards et al. (2009), we captured three elements of each attribution - the source, addressee, and topic. Hence, an attribution of responsibility comprises three pieces of information: who (source) attributes responsibility to whom (addressee) and for what (topic). Through coding, attributions of responsibility were captured in two steps. In the first step, four coders identified and marked all the relevant statements after intensive training that lasted for several weeks. In order to assess the reliability of their identifications of the relevant attributions, we captured all the statements that were identified by one or more of the coders as well as the principal investigator in a dataset. For each of these statements, we recorded for each coder whether they had identified the respective statements or not (yes $=1 ;$ no $=0$ ). Because this procedure did not account for true negatives, i.e., statements that all the coders rightfully did not mark as relevant, we also included all full sentences that none of the coders had marked as relevant to balance their judgments on relevant and irrelevant statements. Overall, the reliability test is based on a 
dataset of 113 cases. Out of these, 68 cases referred to statements at least one of the coders (or the principal investigator) classified as relevant. The remaining 45 cases referred to full sentences that none of the coders had identified as relevant. Based on this dataset, we calculated Krippendorff's Alpha $=0.72$, which indicates that the identification of relevant statements was reliable.

In the second step, 11 coders classified all the statements marked as relevant, capturing each statement's source, addressee, and topic. Classifications of the sources and addressees were very reliable. For the coding of sources' and actors' functions (e.g., as government officials, members of the oppositional party, civil society actors, or others), we obtained a value for Krippendorff's Alpha $=0.82(\mathrm{n}=81)$. For their countries of origin, we obtained a value of Krippendorff's Alpha $=0.94(n=81)$. Coding of the topic of the statements was also reliable, with Krippendorff's Alpha $=0.72(n=45)$. For the coding, we used the python-based coding mask Angrist (Wettstein, 2015), which is particularly suitable for complex and intricate coding schemes.

\section{Data}

The following analysis includes all attributions of negative causal responsibility (blame for failures, $n=534)$ and attributions of treatment $(n=891)$ responsibility. Previous research (e.g., Kepplinger \& Lemke, 2015; Rivenburgh, 2000) has shown that news media's perspectives do not only find expression in their explicit judgments, but also in their selection of or emphasis on particular events and actors' claims. In line with this, we assume that media construct a specific reality through their selections and presentations. Based on this assumption, we counted all attributions of responsibility in the news regardless of the actors cited. Examples of attributions of causal and treatment responsibility to different addressees can be found in table 1 . 
- table 1 about here -

In the coding procedure, we further broadly differentiated among four thematic references. References to climate change / climate change mitigation / climate change adaptation include mentions of causes of or measures against climate change or measures to adapt to it (e.g., a country's plans to cap greenhouse gas emissions, to deforest, or to increase flood protection). References to financial aspects of climate change or climate change mitigation include mentions of the costs of climate change mitigation or of adaptation to climate change (e.g., developing countries' demands of financial aid for adapting to the consequences of climate change). References to international negotiations include mentions of failures or expectations in climate change negotiations (e.g., a country's tactic to block a certain agreement). Other references could include mentions of the science of climate change or climate change as a subject in the arts, and others. By far, most of the attributions of causal and treatment responsibility refer to climate change / climate change mitigation / adaptation to climate change. Far fewer refer to financial questions or to the negotiations (Table 2).

- table 2 about here -

Explicitly, the premise of the developed countries' historic responsibility for climate change refers to the first category (climate change / climate change mitigation / climate change adaptation). Implicitly, however, the historic or "common but differentiated responsibility" can also touch upon other topics because, due to their historic responsibility, developed countries could be evaluated against a higher standard on other dimensions as well. For example, they could be expected to be more conciliatory in international climate talks than developing countries and could be blamed accordingly when failing to meet this expectation. We therefore chose to aggregate the thematic references in our analyses. ${ }^{3}$ 


\section{Results}

\section{Domestic attributions of responsibility}

We assumed that media in developed countries published attributions of responsibility to their own countries more often than did media in emerging economies. This expectation largely holds for attributions of causal responsibility. Media in Australia, Germany and the United States published statements that blamed their respective countries more often than did media in Brazil and India (Table 3, last line). The difference is statistically significant when looking at the years 2004, 2009, and 2014, combined. Overall, about a fourth (26\%) of all blames published in media of developed countries were directed at their respective domestic countries, while only about an eights $(12 \%)$ of all blames published in media of emerging economies were directed at actors from their respective domestic countries. The differences between the two groups of countries are not significant for the years 2004 and 2009. Yet with 8 , respective 11 percentage points of a difference, they markedly point in the same direction. For 2014, the difference between news media in developed countries and emerging economies is significant. This confirms that news media in developed countries selected statements that put the blame for the climate problem on actors from their own countries significantly more often than did news media in emerging economies.

- table 3 and table 4 about here -

The assumption also holds for attributions of treatment responsibility (table 4). Media of the developed countries published statements that saw their own countries in charge of tackling climate change more often than media of countries with emerging economies. Again, the difference is significant when looking at the years 2004, 2009, and 2014, combined. The difference between both groups of countries is very pronounced and significant in news coverage of the COP in Lima, 2014, when media in developed countries published expectations toward their own countries three times more often than did media in emerging 
economies. However, no difference between the two types of countries existed in the coverage of the COPs 2004 and 2009. Overall, the results confirm our expectation that in news coverage in developed countries, the respective domestic societies or governments appeared responsible for climate change more often than in news coverage in emerging economies. Exceptions to this are the years 2004 and 2009, when news media in both groups of countries published statements that held their respective domestic countries responsible for tackling climate change about equally often.

\section{Attributions of responsibility to developed and developing countries}

We expected that in newspapers in developed countries other developed countries appeared less responsible than in newspapers in emerging economies, and that in newspapers in emerging economies, developing countries appeared less responsible than in newspapers in developed countries. For attributions of causal responsibility, this pattern emerges in several cases (table 3, lines 1 through 4). Looking at the three years combined, news media in the developed countries published significantly fewer statements blaming other developed countries than news media in emerging economies. By contrast, newspapers in emerging economies published significantly fewer statements blaming developing countries or emerging economies than did newspapers of the developed countries. The same tendency shows up for news coverage of the COPs in 2004, 2009, and 2014, though the differences are not significant in all cases - possibly partly due to the low numbers of cases. In tendency, newspapers in Brazil and India published fewer statements blaming developing countries than did newspapers in Australia, Germany, and the United States. Conversely, newspapers in Australia, Germany, and the United States published fewer statements blaming other developed countries or regions than did newspapers in Brazil and India. Corroborating this pattern, in 2009 and 2014, newspapers in emerging economies published significantly more statements blaming the US than newspapers in developed countries (table 3, line 4). 
For attributions of treatment responsibility, the assumption only holds in one case. In the context of the news coverage of the COP in Lima, 2014, media of the developed countries published significantly fewer statements that saw other developed countries as in charge of the climate problem than did media in the emerging economies. Against our expectation, for the COP in Copenhagen in 2009, the reverse holds. In that year, media from emerging economies published significantly fewer statements that saw developed countries in charge of the climate problem than did media in developed countries. Also, there is no evidence that media in emerging economies presented developing countries as less responsible for tackling climate change than did news media in developed countries. Thus, there was striking divergence regarding developing and developed countries' responsibility for causing climate change. But there was almost no divergence concerning the developing and developed countries' duties to contribute to solve the climate problem. Strikingly, divergence over countries' duties only emerged in the context of the COP in Lima, 2014, when developed countries or regions appeared much less in charge of solving the climate problem in news coverage in developed countries than in news coverage in emerging economies. Part of the reason for this difference is that in 2014, media of developed countries largely presented their domestic countries as in charge of tackling the climate problem — instead of holding other developed countries responsible.

\section{Attributions of responsibility to countries' in- and out-groups}

We expected that in media coverage in developed countries, developed countries' ingroup would appear more responsible than their out-group, while in media coverage in emerging economies, emerging economies' in-group would appear less responsible than their outgroup. To test this, we created a variable to capture all references to countries' in- and outgroup members; that is, all references in the developed countries' media to their respective domestic countries or to other developed countries were coded as "in-group" - as were all references in emerging economies' media to their respective domestic countries or to other 
developing countries or emerging economies. Likewise, all references in the developed countries' media to developing countries or emerging economies were coded as "out-group" —as were all references in emerging economies' media to developed countries. For both groups of countries, we considered all references to countries' in- and out-groups and calculated the shares of attributions to each group. We then subtracted the share of attributions to countries' in-group from the share of attributions to their out-group. Positive values of this measure indicate that the focus of their responsibility attributions lies on the countries' in-groups, negative values indicate that the focus of their responsibility attributions lies on the countries' outgroups (Figures 1 and 2).

The analyses confirm our expectations. News media in the developed countries largely published statements that blamed their in-group - i.e., their domestic or other developed countries - for climate change or related problems. By contrast, media in emerging economies largely published statements that blamed their out-group - i.e., developed countries. Strikingly, media in developed countries published statements blaming their in-group as much as media in emerging economies published statements blaming their out-group (figure 1). In line with our expectation, media in developed countries also largely presented their in-group, i.e., their domestic or other developed countries, as being in charge of tackling climate change, while media in emerging economies mostly presented their out-group, i.e., developed countries, as the ones in charge. Strikingly, however, media in developed countries presented their in-group as much more in charge than media in emerging economies presented their outgroup as in charge. That is, media in developed countries saw their domestic or other developed countries much more in charge than did media in emerging economies (figure 2).

We further expected that, over time, media in both developed countries and countries with emerging economies shifted the focus of responsibility, assuming that countries' respective in- and out-groups would increasingly be presented as equally responsible. This assumption does not find statistically significant support, even though the data point into the expected 
direction. Over the three points in time, news media in developed countries tended to shift responsibility away from their in-group while media in emerging economies shifted responsibility away from their out-group. Thus, in tendency, media in both types of countries increasingly presented responsibility for climate change as a common responsibility of developed countries and emerging economies (figure 1). For attributions of treatment responsibility, the expected pattern emerges with statistically significant results. The focus in both types of countries converged between 2004 and 2014, as media in developed countries weakened their emphasis on their in-group's duty to solve climate change or related problems. Media in developed countries charged their in-group significantly less often in 2014 than in 2004 and charged their out-group significantly more often in 2014 than in 2004. Media in countries with emerging economies did not shift their focus in a statistically significant way. In all three years, they held their in-group about equally responsible as their out-group (figure 2).

\section{Summary and Discussion}

The present investigation started from the assumption that news media in developed countries and emerging economies acknowledge countries" “common but differentiated responsibility" for climate change in their news coverage. The results of our content analysis of newspaper coverage around three COPs confirm this: News media in developed countries published attributions of responsibility for having caused climate change or for contributing to related problems to their domestic countries considerably more often than media in emerging economies. At the same time, there are indications of in-group protecting patterns in news coverage of causal responsibility. Media in developed countries published statements blaming other developed countries significantly less often than media in emerging economies.

Likewise, media in emerging economies published statements blaming other developing countries or countries with emerging economies significantly less often than media in developed countries. But the results also make clear that attributions of causal responsibility 
in developed countries' media find their limits within the premise of the "common but differentiated responsibility". They clearly blame their own or other developed countries more often than developing countries or countries with emerging economies. This is remarkable as social identity theory predicts and empirical research has found, that in transnational news coverage, in-group / out-group patterns prevail. The limited in-group / out-group pattern we find in this study points at the effectiveness of the international consensus concerning countries' responsibilities for climate change.

In contrast, results on media's attributions of treatment responsibility were not as clear. For example, in some of the years analyzed, media in emerging economies presented developed countries more often in charge of tackling climate change or related problems than did media in developed countries. In 2009, however, media in emerging economies presented developed countries less often in charge of tackling climate change than did media in developed countries. These results raise the question as to what degree attributions of treatment responsibility function as in-group favoring or out-group derogating mechanisms. While negative attributions of causal responsibility, i.e., accusations or blames, can surely function to put an out-group in a negative light, charges of treatment responsibility to the outgroup may actually appear to put it into power. Liang et al. (2014) point toward this direction finding that media's attributions of treatment responsibility often come along with statements about countries' political efficacy. In 2009, actors in emerging economies might have avoided shifting too much responsibility to developed countries in order not to attribute too much power to them. This was a time when emerging economies became actively engaged in international climate change politics with the goal of appearing as powerful partners in the negotiations (Hallding et al., 2013). This seems to have found expression in news coverage. In 2009, newspapers in emerging economies largely shifted responsibility away from developed countries to the supranational level - i.e. to the UN, the UNFCCC process or the international community. They did so significantly more often than did media in developed countries in 
2009 and 2014 (table 4, line 6). In terms of social identity theory, these results call for future studies that clarify the functions of the different types of attributions of responsibility as ingroup protecting strategies in news coverage of international negotiations.

Researchers have argued that the global threat of climate change might facilitate a global public sphere (Beck, 2007, 34; Eide \& Kunelius, 2010), rendering national identities less salient and giving way to a collective global identity. From the perspective of social identity theory this would imply that in-group / out-group perceptions decrease, that responsibility for climate change becomes less contested and more commonly accepted. We tested this assumption by comparing three points in time. In tendency, we found that in newspapers of developed countries and emerging economies, countries' respective in- and out-groups were increasingly presented as equally responsible both for causing and for tackling climate change. However, the results were only significant for media in developed countries that, between 2004 and 2014, shifted responsibility for tackling climate change away from their in-group to their out-group.

Recent developments suggest that transnational conflicts over climate change policies might not decrease but aggravate. With the United States quitting the Paris Agreement, developed and developing countries might start renegotiating their equity shares in climate change mitigation. The conflict over climate change policies might also intensify as climate change becomes more of a threat and increases pressure on the international community. In light of these developments, it seems desirable to continue to investigate national news coverage of the international debate on climate change. Future studies should further clarify the existence of in-group / out-group biases in national news about international negotiations and redeem some of the limitations of the present study - e.g. rely on larger samples of media contents and consider more than the five countries considered here. It would also be desirable to investigate how national media coverage of international climate politics has developed since the Paris Agreement. In longitudinal analyses, it would be desirable to include more 
points in time in the investigation. What is more, in future studies, researchers might want to test whether in-group / out-group biases find expression in other patterns beyond attributions of causal responsibility—-for example, in particular news frames or narratives. Such efforts would be particularly desirable as, telling from the present study, applications of social identity theory appear to be a fertile approach to analyzing national reporting on the international climate change negotiations.

\footnotetext{
${ }^{1}$ Some newspapers cannot be retrieved from Factiva or LexisNexis (e.g. the Frankfurter Allgemeine Zeitung in Germany). In such cases, we used the digital archives applying the search criteria described above.

${ }^{2}$ For each COP we analyzed one week before, the time period during the COP, and one week after the COP. The concrete dates were as follows: COP 2004 in Buenos Aires: November $29^{\text {th }}-$ December $24^{\text {th }}$. COP in 2009 in Copenhagen: November $30^{\text {th }}-$ December $25^{\text {th }}$. COP 2014 in Lima: November $24^{\text {th }}-$ December $19^{\text {th }}$

${ }^{3}$ As a robustness check, we checked whether the results differed when using the topic of the first category (climate change / climate change mitigation / adaption) only. Essentially, results did not differ from the results presented here.
} 


\section{References}

Bernauer, T. (2013). Climate change politics. Annual Review of Political Science, 16, 421448.

Billett, S. (2010). Dividing climate change: global warming in the Indian mass media. Climatic Change, 99(1), 1-16.

Broadbent, J., Sonnett, J., Botetzagias, I., Carson, M., Carvalho, A., Chien, Y. J., Hasegawa, K., et al. (2016). Conflicting climate change frames in a global field of media discourse. Socius, 2, 2378023116670660.

Brunnée, J., \& Streck, C. (2013). The UNFCCC as a negotiation forum: towards common but more differentiated responsibilities. Climate Policy, 13(5), 589-607.

Entman, R. M. (1991). Symposium framing US coverage of international news: Contrasts in narratives of the KAL and Iran air incidents. Journal of Communication, 41(4), 6-27.

Esses V. M., Jackson L. M., Bennett-AbuAyyash C. (2011). Intergroup competition. In Dovidio J. F., Hewstone M., Glick P., \& Esses V. (Eds.), The Sage handbook of prejudice, stereotyping and discrimination (pp. 225-40). London: SAGE.

Fiske, S. T. \& Russell, A.M. (2011). Cognitive Processes. In J. F. Dovidio, M. Hewstone, P. Glick, \& V. Esses (Eds.), The Sage handbook of prejudice, stereotyping and discrimination (pp. 115-30). London: SAGE.

Friman, M., \& Hjerpe, M. (2015). Agreement, significance, and understandings of historical responsibility in climate change negotiations. Climate Policy, 15(3), 302-320.

Füssel, H. M. (2010). How inequitable is the global distribution of responsibility, capability, and vulnerability to climate change: A comprehensive indicator-based assessment. Global Environmental Change, 20(4), 597-611. 
Gaertner, S. L., Dovidio, J. F., \& Houlette, M. A. (2010). Social Categorization. In J. F. Dovidio, M. Hewstone, P. Glick, \& V. Esses (Eds.), The Sage handbook of prejudice, stereotyping and discrimination (pp. 526-43). London: SAGE.

Genovese, F. (2014). States' interests at international climate negotiations: new measures of bargaining positions. Environmental Politics, 23(4), 610-631.

Gerhards, J., Offerhaus, A., \& Roose, J. (2009). Wer ist verantwortlich? Die Europäische Union, ihre Nationalstaaten und die massenmediale Attribution von Verantwortung für Erfolge und Misserfolge. In: Marcinkowski, F. and Pfetsch, B. (Eds.), Politik in der Mediendemokratie (pp. 529-558). VS Verlag für Sozialwissenschaften.

Gupta, J. (2010). A history of international climate change policy. Wiley Interdisciplinary Reviews: Climate Change 1, 636-653.

Hallding, K., Jürisoo, M., Carson, M., \& Atteridge, A. (2013). Rising powers: the evolving role of BASIC countries. Climate policy, 13(5), 608-631.

Hallin, D. C., \& Mancini, P. (2004). Comparing media systems: Three models of media and politics. Cambridge University Press.

Haßler, J. (2016). Mediatisierung der Klimapolitik: Eine vergleichende Input-Output-Analyse zur Übernahme der Medienlogik durch die Politik. Springer-Verlag.

Huggel, C., Wallimann-Helmer, I., Stone, D., \& Cramer, W. (2016). Reconciling justice and attribution research to advance climate policy. Nature Climate Change, 6(10), 901908.

Iyengar, S. (1989). How citizens think about national issues: A matter of responsibility. American Journal of Political Science, 878-900.

Johannessen, J. (2015). Worldview struggles under a new climate regime. Nordicom Review, 36(1), 35-49.

Jones, T. M., \& Sheets, P. (2009). Torture in the eye of the beholder: Social identity, news coverage, and Abu Ghraib. Political Communication, 26(3), 278-295. 
Kepplinger, H. M., Brosius, H. B., \& Staab, J. F. (1991). Instrumental actualization: A theory of mediated conflicts. European Journal of Communication, 6(3), 263-290.

Kepplinger, H. M., \& Lemke, R. (2016). Instrumentalizing Fukushima: comparing media coverage of Fukushima in Germany, France, the United Kingdom, and Switzerland. Political Communication, 33(3), 351-373.

Kleinen-von Königslöw, K., Post, S. \& Schäfer, M.S. (2017). How Domestic Media (De)Legitimize Climate Politics. A Content Analysis of Newspaper Coverage in Five Countries. Paper presented at the Annual Conference of the German Communication Association March 2017.

Leyens, J.-P. \& Demoulin, S. (2011). Ethnocentrism and group realities. In Dovidio J. F., Hewstone M., Glick P., Esses V. (Eds.), The Sage handbook of prejudice, stereotyping and discrimination (pp. 194-208). London: SAGE.

Liang, X., Tsai, J. Y., Mattis, K., Konieczna, M., \& Dunwoody, S. (2014). Exploring attribution of responsibility in a cross-national study of TV news coverage of the 2009 United Nations Climate Change Conference in Copenhagen. Journal of Broadcasting \& Electronic Media, 58(2), 253-271.

Michaelowa, K., \& Michaelowa, A. (2012). India as an emerging power in international climate negotiations. Climate Policy, 12(5), 575-590.

Müller, P. (2013). National identity building through patterns of an international third-person perception in news coverage. International Communication Gazette, 75(8), 732-749.

Müller, P. (2016). National identity building as a mediated process: A two-level model of its functions and dysfunctions. In P. Schmidt, J. Seethaler, L. Huddy, \& J. Grimm (Eds.), Dynamics of National Identity. Media and Societal Factors of What We Are (pp. 319-333). Abingdon: Routledge.

Najam, A., Huq, S., \& Sokona, Y. (2003). Climate negotiations beyond Kyoto: developing countries concerns and interests. Climate Policy, 3(3), 221-231. 
Olausson, U. (2009). Global warming_-global responsibility? Media frames of collective action and scientific certainty. Public Understanding of Science, 18(4), 421-436.

Rivenburgh, N. K. (2000). Social identity theory and new portrayals of citizens involved in international affairs. Media Psychology, 2(4), 303-329.

Schäfer, M. S., Ivanova, A., \& Schmidt, A. (2014). What drives media attention for climate change? Explaining issue attention in Australian, German and Indian print media from 1996 to 2010. International Communication Gazette, 76(2), 152-176.

Scharkow, M. (2012). Automatische Inhaltsanalyse und maschinelles Lernen. epubli.

Schmidt, A., Ivanova, A., \& Schäfer, M. S. (2013). Media attention for climate change around the world: A comparative analysis of newspaper coverage in 27 countries. Global Environmental Change, 23(5), 1233-1248.

Schmidt, A., \& Schäfer, M. S. (2015). Constructions of climate justice in German, Indian and US media. Climatic Change, 133(3), 535-549.

Snider, J. H. \& Janda. K. (1998): Newpapers in Bytes and Bits: Limitations of Electronic Databases for Content Analysis. Paper delivered at the 1998 Annual Meeting of the American Political Science Association, Boston, September 3-6, 1998.

Stiehler, H. J., \& Marr, M. (1994). Zwei Fehler sind gemacht worden, und deshalb sind wir nicht mehr im Wettbewerb: Erklärungsmuster der Medien und des Publikums in der Kommentierung des Scheiterns der deutschen Nationalmannschaft bei der FußballWeltmeisterschaft, Rundfunk und Fernsehen, 43(3), 330-349.

Wettstein, M. (2014). Angrist 1.2: Documentation and Reference for the Coder Interface. Retrieved from http://www.ipmz.uzh.ch/Abteilungen/Medienpsychologie/Recource/Angrist/ ANGRIST_1-2-en.pdf. 
Tajfel, H., \& Turner, J. C. (1986). The social identity theory of intergroup behavior. In S. Worchel \& W. G. Austin (Eds.), Psychology of Intergroup Relations (pp. 2-24). Chicago: Nelson. 